\title{
Association of Maedi Visna virus with Brucella ovis infection in rams
}

\author{
S. Preziuso, ${ }^{*}$ E. Sanna, ${ }^{\circ}$ M.P. Sanna, ${ }^{\circ}$ C. Loddo, ${ }^{\circ}$ D. Cerri, ${ }^{*}$ E. Taccini, ${ }^{*}$ F. Mariotti, ${ }^{*}$ G. Braca, ${ }^{*}$ \\ G. Rossi," G. Renzoni" \\ *Dip. di Patologia Animale, Facoltà di Medicina Veterinaria, Università degli Studi di Pisa; *Istituto di \\ Patologia Generale, Anatomia Patologica e Clinica Ostetrico-Chirurgica Veterinaria, Facoltà di Medicina \\ Veterinaria, Università di Sassari; "Dipartimento di Scienze Veterinarie, Facoltà di Medicina Veterinaria, \\ Università di Camerino, Italy
}

(C)2003, European Journal of Histochemistry

Maedi Visna Virus (MVV) is the etiological agent of a systemic disease of sheep, which causes lesions in lungs, the central nervous system, joints, and mammary glands. It has been speculated that the association with Brucella ovis may lead to the venereal shedding of the virus. In this work, samples of epididymis from ten rams positive for MVV and infected experimentally with Brucella ovis, were subjected to liquid-phase PCR, immunohistochemistry (IHC) and in situ PCR tests, aimed at identifying the pathogens in a tissue context. IHC was carried out using a monoclonal antibody raised against p28 MVV protein and a polyclonal antibody to $B$. ovis. Liquid phase- and in situ PCR were designed to amplify a portion of MVV proviral DNA Pol sequence. In the animals showing $B$. ovis-related histopathological changes, IHC clearly demonstrated a positivity for $B$. ovis and MVV in interstitial and epithelial ductal cells. In situ PCR assessed the presence of MVV proviral DNA in macrophages and elements inside the epithelium. The unaffected and reagent control samples constantly gave negative results. Taken together, these data demonstrate that MVV may affect ovine epididymis, apparently taking advantage of the concurrent infection by $B$. ovis. The tropism of MVV for the epididymal epithelial cells, may be responsible for its excretion with the semen.

Key words: Maedi Visna Virus, Brucella ovis, sheep, immunohistochemistry, in situ-PCR.

Correspondence: Professor Ennio Sanna, Istituto di Patologia Generale, Anatomia Patologica e Clinica Ostetrico-Chirurgica Veterinaria, Facoltà di Medicina Veterinaria, Università degli Studi di Sassari, via Vienna 2, 07100 Sassari, Italy. Phone: international +39.079.229441. Fax: international +39.079. 229415. E-mail: patvetss@ssmain.uniss.it

Paper accepted on December 9, 2002

European Journal of Histochemistry 2003; vol. 47 issue 2 [Apr-Jun]:151-158
$\mathrm{M}$ aedi Visna Virus (MVV) is a lentivirus which affects sheep in several countries of Europe, Africa and Asia and in the USA. It is responsible for progressive inflammatory diseases of the lungs, mammary glands, joints and central nervous system (Brodie et al., 1998, Pepin et al., 1998). The major site of viral replication is represented by the monocyte-macrophage lineage, but specific tropisms for other cell types have been reported (Brodie et al., 1995). The virus is usually transmitted via respiratory aerosol and milk, but other excretion routes, including the venereal, cannot be excluded.

The shedding of lentiviruses in semen has been well documented in primates. In humans, it is considered one of the main routes of human immunodeficiency virus transmission (Krieger et al., 1991; Kurth et al., 1991). In rhesus macaques, Miller et al. (1994) detected the simian immunodeficiency virus (SIV) in epididymal macrophages and T-cells by means of immunohistochemistry (IHC) and in situ hybridisation (ISH).

With regard to $M V V$, its presence in the semen has been assessed in rams concurrently affected by Brucella ovis (De la Concha-Bermejillo et al., 1996). These data, obtained by virus isolation and liquid-phase procedures, have led to the speculation that the venereal transmission of MVV plays an important role in the epidemiology of this infection.

In this study, we have investigated the localisation of MVV in the epididymis of rams experimentally infected with $B$. ovis, in order to identify the involved cells in a tissue context, and to confirm the relevance of this concurrent infection in the transmission of the retroviral disease.

\section{Materials and Methods}

\section{Experimental infection}

Ten Massese breed rams, aged 4-5 months, seronegative for $B$. ovis and $B$. melitensis, were 


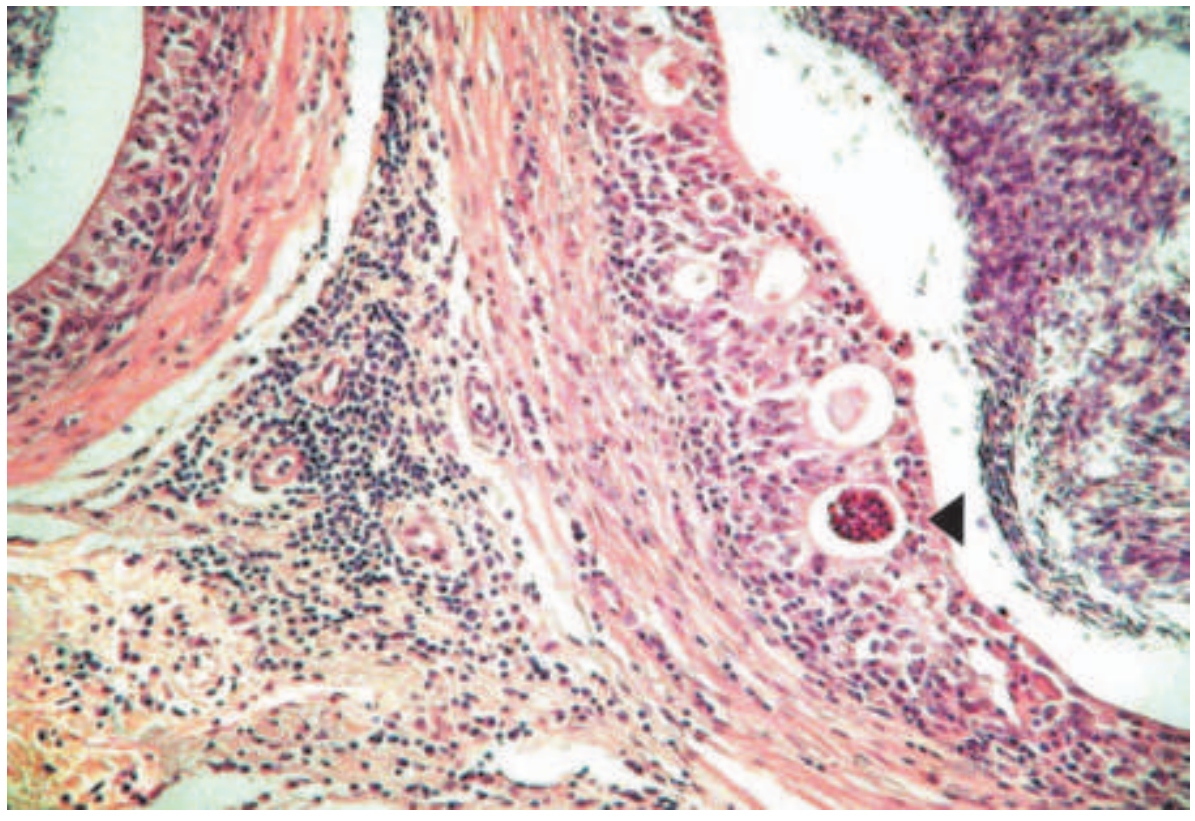

Figure 1. Ram epididymis affected by Brucella ovis. Interstitial flogosis, hyperplasia and microabscesses in the epidydimus (arrowhead). Spermatozoa are present in the lumen. H.E. $\times 10$. experimentally infected by conjunctival instillation of a solution containing $B$. ovis (strain $B G 1 / 94$ ) at a titre of $2.4 \times 10^{9} \mathrm{UFC} / \mathrm{mL}$ (Farina et al., 1995). The animals received $0.25 \mathrm{~mL}$ of the inoculum in each eye. Blood samples were taken weekly from all the rams. Serological tests were performed according to the protocol reported by Cerri et al. (1999). ELISA tests for MVV were also carried out on all the subjects as previously described (Saman et al., 1999).

\section{Post-mortem exams}

The seropositive rams for $B$. ovis were sacrificed at intervals of fifteen days starting from nine weeks after inoculation, and complete necropsies were carried out. Epididymal samples were subjected to bacteriological tests as previously described (Cerri et al., 1999). Tissue samples from epididymis and lungs from all the animals were fixed in $10 \%$ formalin and paraffin wax-embedded.

\section{Histopathology and Immunohistochemistry (IHC)}

Sections $(5 \mu \mathrm{m})$ prepared by routine methods, were examined after staining with haematoxylin and eosin. IHC was performed on the epididymal tissues to reveal the presence of $B$. ovis. Selected sections were labelled immunohistochemically with a commercial avidin-biotin alkaline phosphatase complex kit (Vectastain ABC Kit; Vector Laboratories, Burlingame, CA, USA) after microwave pre-treat- ment (10 min at $650 \mathrm{~W}$ ). Selected sections were incubated overnight at $4^{\circ} \mathrm{C}$ with a primary rabbit antiserum to $B$. ovis, used at the predetermined optimal dilution of 1:500, raised at the Department of Animal Pathology, Pisa, Italy (Cerri et al., 1999). The specific sera were replaced with Tris-buffered saline (TBS) or pre-immunization sera as a control for non-specific reactions. As negative control, tissues from non infected rams were used. The reactions were developed with alkaline-phosphatase. Harris' hematoxylin was used as a counterstain.

Epididymal and lung samples from all the subjects were also subjected to IHC tests specific for the detection of MVV. A monoclonal antibody to the p28 core protein (VMRD, Pullman, WA, USA) was used at the pre-determined optimal dilution of 1:500. The reactions were carried out accordingly with a protocol previously reported (Renzoni et al., 1995), and diaminobenzidine (DAB) was used to develop the reactions.

\section{Liquid-phase PCR}

DNA was extracted from paraffin wax-embedded samples of lungs and epididymi by a lysis buffer method, as previously described (Wright and Manos, 1990). A nested PCR was performed to amplify a portion of the MVV proviral DNA Pol region.

In the first step, a couple of primers (sense 4231: 5'ATAGTAAATGGCATCAAGATGC3'; antisense 4448 5'TCCCGAATTTGTTTCTACCC 3') was used 


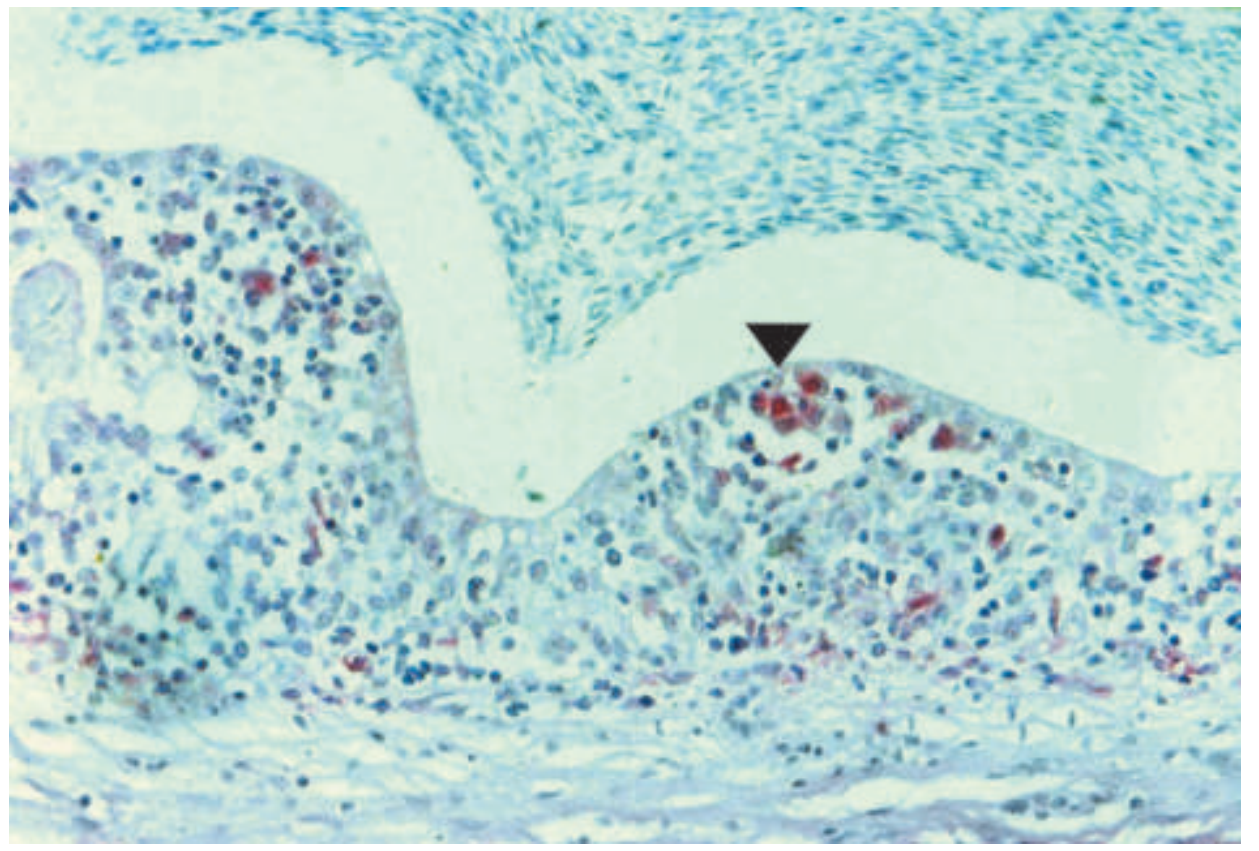

Figure 2. Ram epididymis. Immunohistochemistry for $B$. ovis. Some epithelial cells are labelled by the chromogen (arrowhead). Haematoxilin counterstain. $\times 25$. to amplify a $218 \mathrm{bp}$ sequence. The PCR mixture contained $1 \times$ PCR buffer $5 \mu \mathrm{L}, 3.5 \mathrm{mM} \mathrm{MgCl}$, $200 \mu \mathrm{M}$ dNTP mix, $0.5 \mu \mathrm{M}$ sense primer, $0.5 \mu \mathrm{M}$ antisense primer, Taq 2 units, DNA template 1700 $\mathrm{ng}$, and $\mathrm{H} 20$ (up to a total volume of $50 \mu \mathrm{L}$ each sample). The amplification process consisted of one cycle at $95^{\circ} \mathrm{C}$ for $5 \mathrm{~min}$, followed by 30 cycles at $95^{\circ} \mathrm{C}$ for $1 \mathrm{~min}, 59^{\circ} \mathrm{C}$ for $1 \mathrm{~min}, 72^{\circ} \mathrm{C}$ for $1 \mathrm{~min}$, with a final extension at $72^{\circ} \mathrm{C}$ for 2 min.

In the second step, a couple of primers (Sense 4257 5' - TCATTGCATCTAGAA TTT G - 3'; antisense $43985^{\prime}$ - TGTAATCCACTTGCCAAT - 3') was designed to target a $142 \mathrm{bp}$ sequence internal to the previously amplified portion. The composition of PCR mixture was the same as used in the first step, and, as a template, $1.5 \mu \mathrm{L}$ of the first PCR products were employed. The amplification was performed at the following conditions: $95^{\circ} \mathrm{C}$ for $5 \mathrm{~min}$, followed by 35 cycles at $95^{\circ} \mathrm{C}$ for $1 \mathrm{~min}, 48^{\circ} \mathrm{C}$ for $1 \mathrm{~min}, 72^{\circ} \mathrm{C}$ for $1 \mathrm{~min}$, with a final extension at $72^{\circ} \mathrm{C}$ for $2 \mathrm{~min}$. The PCR products were then analysed by agarose gel electophoresis. Reagent and negative (unaffected) controls were used to check the specificity of the reaction.

\section{In situ PCR (IS-PCR)}

All stages of the in situ protocol were performed with a capillary gap system (Microprobe; Biomeda, Foster City, CA, USA) with the exception of amplification and hybridization. Sections $(5 \mathrm{~mm})$ of epi- didymis and lung samples from all the subjects were mounted on special capillary gap slides, and pretreatments, hybridization, and post-hybridization procedures were performed as previously reported (Sanna et al., 1999). The PCR was designed to amplify a 218 bp sequence of MVV proviral DNA Pol region; we used the same primers employed in the first step of liquid phase PCR, and the PCR mixture contained $3 \mathrm{mM} \mathrm{MgCl2,} 200 \mathrm{mM}$ dNTP mix, $10 \times$ PCR buffer $5 \mathrm{ml}, 0.2 \mathrm{mM}$ sense primer, 0.2 $\mathrm{mM}$ antisense primer, Taq 1.25 units, and $\mathrm{H} 20$ up to a total volume of $50 \mathrm{ml}$ per slide. Coverslips were added and sealed with Hybaid Easy Seal Starter Kit (Hybaid Ltd., Waldegrave, Teddington, Middlesex, UK). The amplification process consisted of one cycle at $95^{\circ} \mathrm{C}$ for $5 \mathrm{~min}$, followed by 30 cycles at $95^{\circ} \mathrm{C}$ for $1 \mathrm{~min}, 59^{\circ} \mathrm{C}$ for $1 \mathrm{~min}$, with a final extension at $72^{\circ} \mathrm{C}$ for $2 \mathrm{~min}$, and it was performed in an in situ thermal cycler (Hybaid Omnislide 2000). After completion of the PCR, the slides were retransferred into the capillary slide-holder, washed three times (10 min each step) with phosphatebuffered saline (PBS), post-fixed for 2 min in $4 \%$ paraformaldehyde and re-washed with PBS for 1 min. Slides were then hybridized with an internal digoxygenin-labelled probe ( $5^{\prime}$ CATTGGCAAGTGGATT $3^{\prime}$ ), diluted in hybridization solution IV (Fluka Chemika-Biochemika, Buchs, Switzerland). Reagent and unaffected controls (lung samples negative for MVV, and rabbit kidneys) were used. 

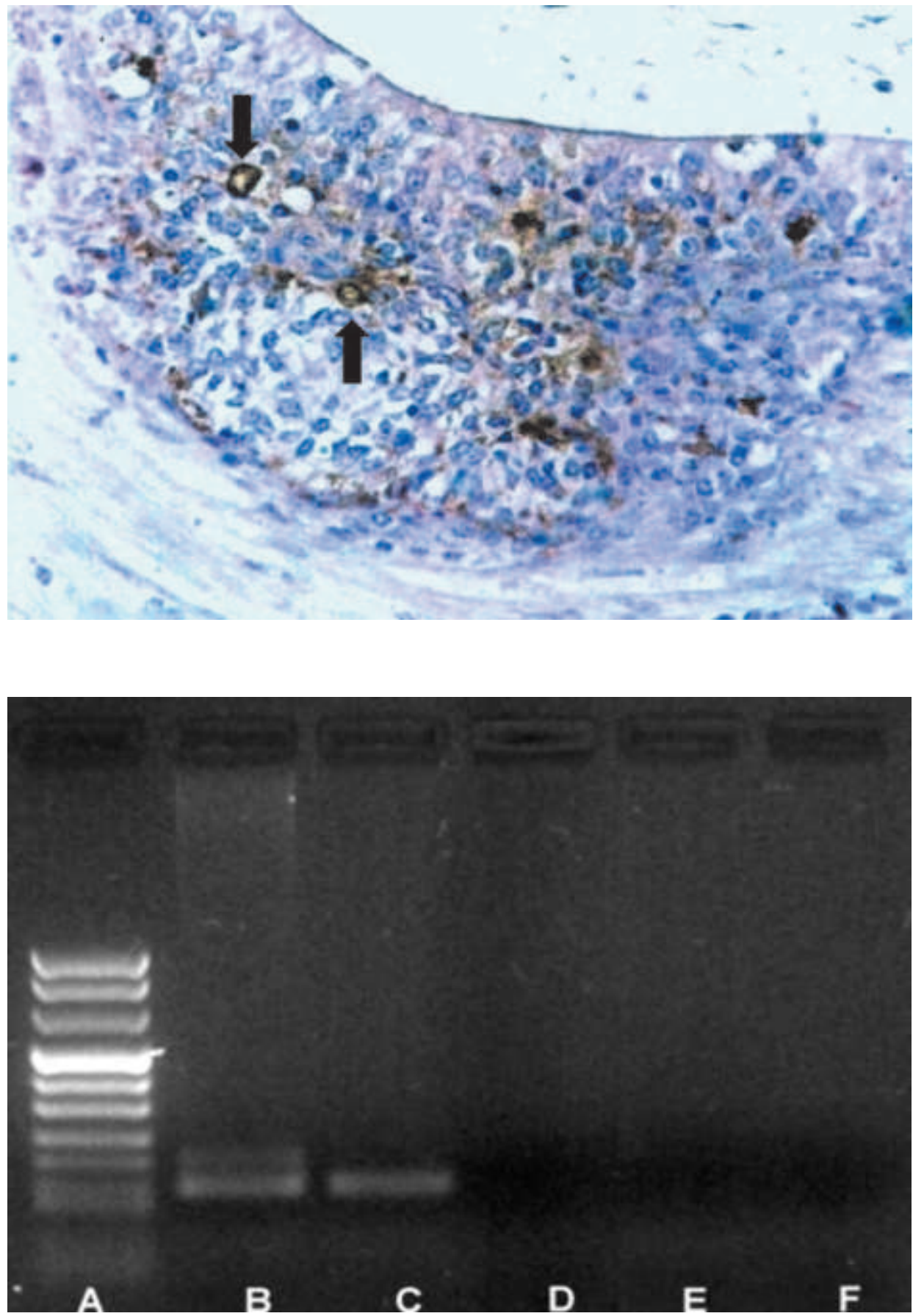

Figure 3. Ram epididymis. Immunohistochemistry for MVV p28. Clear positivity inside the epithelium (arrows). Hematoxylin counterstain. $\times \mathbf{4 0}$.
Figure. 4. Nested Pol PCR employed to detect MVV proviral DNA from paraffin wax block samples. Lane A: molecular weight standards, Boehringer VIII. Lanes B-C: epididymal samples from rams showing $B$. ovisrelated lesions. Lane D: epididymal sample from a ram negative for B. ovis-related lesions. Lanes E-F: unaffected and reagent control samples.

\section{Results}

\section{Experimental infection and post-mortem findings}

Between 2 and 5 weeks after infection, all the ten rams became seropositive for Brucella ovis, which was isolated from epididymis of two rams, and from the blood of all the animals with the exception of one subject. ELISA tests for MVV constantly gave negative results. At necropsy, no gross finding was detected.

\section{Histopathology}

The histopathological examination revealed $B$. ovis-related lesions only in the two rams in which mature spermatozoa were present in the lumen of the epididymis (Figure 1). These subjects showed hyperplasia of the epididymal epithelium, microabscesses in the ducts, and oedema, perivascular cuffing and infiltration of lymphocytes, plasmacells and neutrophils in the interstitium (Figure 1). 

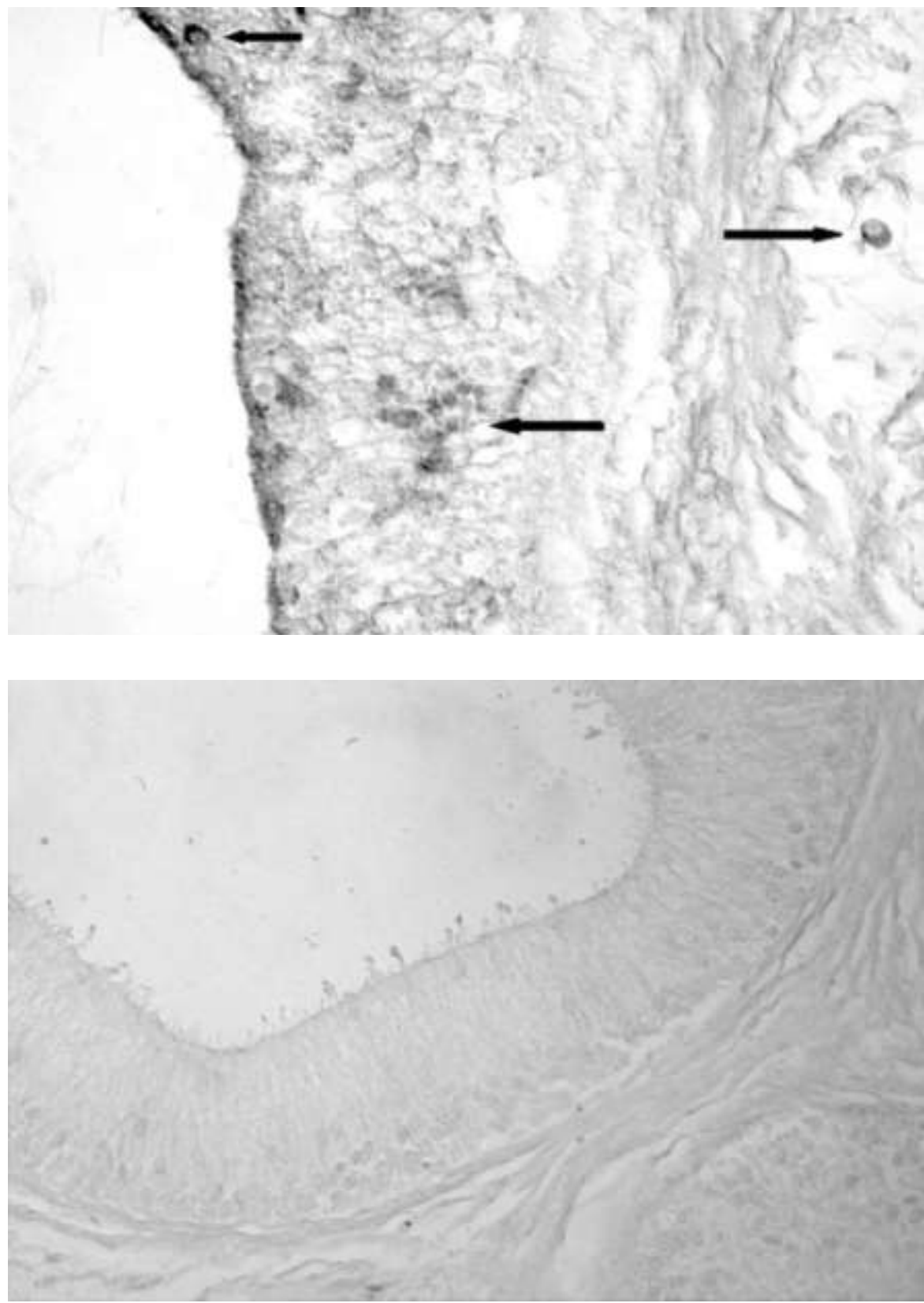

Figure 5. Ram epididymis from a subject presenting $B$. ovis-related lesions. IS-PCR for Pol MVV proviral DNA. A macrophage in the interstitium and some elements in the epithelium are clearly labelled (arrows). X 40.

Figure 6. Ram epididymis from a subject not presenting $B$. ovis-related lesions. IS-PCR for Pol MVV proviral DNA: absence of signals. $\times 25$.

Six animals (including those presenting the epididymal changes), showed lung lesions which were indicative of a MVV infection. They consisted of a thickening of the alveolar walls and an interstitial chronic flogosis with typical lymphatic clusters scattered in the parenchyma.

\section{Immunohistochemistry}

IHC for B. ovis gave positive results in the two rams which had shown appreciable histological epididymal lesions. A clear labelling was observed in mononuclear and epithelial ductal cells (Figure 2).
IHC for MVV revealed the presence of the p28 viral core protein in the lungs of the rams presenting MVV-related microscopical lesions. MVV was mainly associated with alveolar and interstitial macrophages, but it was also present inside the lymphatic clusters. In the epididymis context, positive results were obtained only in the two animals which had shown immunohistochemical positivity for B. ovis. The signals were associated with interstitial macrophages, and epithelial ductal elements (Figure 3). No result was obtained from negative and reagent controls. 


\section{Liquid phase-PCR}

DNA extracted from paraffin wax blocks was subjected to PCR amplification of MVV proviral DNA. A product of the expected size (142 bp) was observed in the samples which had shown immunohistochemical positivity for p28 MVV protein. No product was obtained from lung and epididymal samples from the other animals and from a healthy sheep lung kept as a negative control throughout the procedure (Figure 4).

\section{In situ-PCR}

The in situ PCR disclosed in the two subjects immunohistochemically positive for B. ovis, a number of cells that contained a dark blue pigment, the signal for amplified MVV proviral DNA. The positive areas corresponded to interstitial macrophages located near the ducts, and elements scattered in the epithelium (Figure 5). The unaffected and reagent control samples constantly gave negative results (Figure 6).

\section{Discussion}

This work was initially conducted to study the lesions caused by $B$. ovis and the pathogen distribution following experimental infection. As we were carrying out extensive studies on MVV infection, lung samples were also taken from the rams subjected to the experimental infection, and IHC, specific for MVV p28 protein was performed. Surprisingly, we were able to assess that some animals were immunohistochemically positive for MVV. The presence of the lentivirus was then confirmed by liquid phase PCR tests. Such observations appear to be in contrast with the results of the ELISA tests for MVV, but this could be compatible with previous findings of seronegativity that usually follows the colostral immunity received by the lambs. (Brodie et al., 1995).

In the epididymi positive for $B$. ovis, prominent lesions were observed, with an involvement of both interstitial and ductal structures that substantially corresponded to those described in the literature (Ladds, 1993). IHC clearly showed that the bacterium was associated with the reported lesions. Interestingly, at the epididymal level, IHC for MVV gave good results only in the two rams which were positive for $B$. ovis by immunohistochemistry. The tissue distribution of the two pathogens matched well, as MVV p28 protein was found in interstitial macrophages at the inflamed sites and inside the affected epithelium. These observations were confirmed by IS-PCR, which disclosed positive signals arising from the same areas. It is remarkable that not all the subjects presenting lymphoproliferative lesions in the lung, whose IHC and liquid-phase PCR tests for MVV were positive, showed a similar labelling at the epididymal level.

Evaluated together, these data demonstrate that MVV may affect ovine epididymis, apparently taking advantage of the concurrent infection by $B$. ovis. As the ovine epididymis is not a usual target organ for MVV, its involvement may be facilitated in consequence of monocyte/macrophages recruitment and activation that occurs during the bacterial infection.

The presence of the lentivirus in an epithelial context, as demonstrated by both IHC and IS-PCR, is very interesting. MVV proviral DNA in cells other than macrophages had been described by Staskus et al. (1991), but Brodie et al. (1995) assessed that the virus could enter a variety of cell types, but productive infection was restricted to cells of macrophage lineage in affected tissues. Our IHC results show that the presence of MVV in the epidydimal ductal cells is productive. Similar results were obtained by some of us on mammary glands subjected to experimental infection, and, also on that occasion, IHC and IS-PCR data matched very well (Vitali et al., 1997); on the other hand, we had demonstrated that caprine arthritis encephalitis virus, a lentivirus strictly related to MVV, shows a tropism for a broad cell spectrum; ependymal epithelia, for example, seemed to play a crucial role in the diffusion of the disease to different CNS districts via cerebrospinal fluid (Sanna et al., 1999). Recently, MVV proteins were found in the cytoplasm of ovine bronchiolo-alveolar elements (Gelmetti et al., 2000), dendritic cells (Ryan et al., 2000), and microglial cells (Ebrahimi et al., 2000). Thus, the infection of the epithelial cells in the epididymal context may be considered as not surprising at all.

A question to be answered is how the epithelial layers could become infected. Probably, the macrophages in the inflamed areas may act as a reservoir for viral infection, and facilitate the spreading of the virus towards the ductal structures. In any case, the presence of MVV-infected cells in the epididymal epithelia highlights the possibility that sperm of infected rams may contain 
viral particles as a consequence of cell turnover. This possibility may per se increase the risk of disease transmission via semen.

\section{Acknowledgments}

The authors are grateful to Prof. F. Tolari, from the Department of Animal Pathology, University of Pisa, to have carried out the ELISA tests for MVV. This research was supported by funds from the Italian Ministero dell'Università e della Ricerca Scientifica e Tecnologica.

\section{References}

Brodie SJ, de la Concha-Bermejillo A, Snowder GD, De Martini JC. Current concepts in the epizootiology, diagnosis, and economic importance of ovine progressive pneumonia in North America: a review. Small Ruminant Res 1998;27:1-17.

Brodie SJ, Pearson LD, Zink MC, Bickle HM, Anderson BC, Marcom $K A$, et al. Ovine lentivirus expression and disease. Virus replication but not entry, is restricted to macrophages of specific tissues. Am J Pathol 1995; 146:250-63.

Cerri D, Ebani VV, Pedrini A, Nuvoloni R, Renzoni G, Andreani E, et al. Epididymitis by Brucella ovis: experimental infection in virgin ram lambs. Microbiologica 1999;22:227-31.

De la Concha-Bermejillo A, Magnus-Corral S, Brodie SJ, DeMartini, $\mathrm{JC}$. Venereal shedding of ovine lentivirus in infected rams. Am J Vet Res 1996;57:684-8.

Ebrahimi B, Allsopp TE, Fazakerley JK, Harkiss GD. Phenotypic characterisation and infection of ovine microglial cells with Maedi-Visna virus. J Neurovirol 2000;6:320-8.

Farina R, Cerri D, Andreani E, Renzoni G, Guadagnini PF, Lombardi G. Epididimite dei montoni: prima segnalazione sulla presenza di Brucella ovis in Italia. Selezione Veterinaria 1995;36:285-91.

Gelmetti D, Gibelli L, Brocchi E, Cammarata G. Using a panel of mon- oclonal antibodies to detect Maedi virus (MV) in chronic pulmonary distress of sheep. J Virol Methods 2000;889-14.

Krieger JN, Coombs RW, Collier AC, Ross S, Chaloupka K, Cummings DK, et al. Recovery of human immunodeficiency virus type 1 from semen: minimal impact of stage of infection and current antiviral chemotherapy. J Infect Dis 1991;163:386-8.

Kurth R, Baier M, Binninger D, Cichutek K, Lower J, Norley S. Epidemiology and pathogenicity of humans retroviruses. Dev Biol Stand 1991;75:105-11.

Ladds PW. The male genital system. In: Pathology of domestic animals. vol. 2, $4^{\text {th }}$ Edition, Jubb KVF, Kennedy PC, Palmer N, Eds. Academic Press: San Diego; 1993. p. 461-529.

Miller CJ, Vogel P, Alexander NJ, Dandekar S, Hendrickx AG, Marx PA. Pathology and localization of simian immunodeficiency virus in the reproductive tract of chronically infected male rhesus macaques. Lab Invest 1994;70:255-62.

Pepin M, Vitu C, Russo P, Mornex JF, Peterhans E. Maedi-Visna virus infection in sheep: a review. Vet Res 1998;29:341-67.

Renzoni G, Taccini E, Lossi L, Rossi G, Braca G. Thyroid C-cell carcinoma in a sheep: histopathological and immunocytochemical study. Vet Pathol 1995;32:727-30.

Ryan S, Tiley L, McConnell I, Blacklaws B. Infection of dendritic cells by the Maedi-Visna lentivirus. J Virol 2000;74:10096-103.

Saman E, Van Eyden G, Lujan L, Extramiana B, Harkiss G, Tolari F, et al. A new sensitive serological assay for detection of lentivirus infections in small ruminants. Clin Diagn Lab Immun 1999;6:734-40.

Sanna E, Sanna MP Vitali CG, Renzoni G, Sanna L, Spano S, et al. Proviral DNA in the brains of goats infected with Caprine Arthritis Encephalitis Virus. J Comp Pathol 1999;121:271-6.

Staskus KA, Couch L, Bitterman P, Retzel EF, Zupancic M, List J, et al. In situ amplification of Visna virus DNA in tissue sections reveals a reservoir of latently infected cells. Microb Pathogenesis 1991; 11:67-76.

Vitali CG, Sanna E, Braca G, Boero L, Rossi G, Leoni A. In situ techniques for the detection of proviral DNA in sheep mastitis caused by MVV (Conference abstract). In: Proceedings of the Third European Workshop on Ovine and Caprine Retroviruses. J.J. Badiola, Ed. Jaca; 1997. p. 23.

Wright D, Manos M. Sample preparations from paraffin-embedded tissues. In PCR protocols, a guide to methods and applications. Innis MA, Gelfand DH, Sninsky JJ, White TJ, Eds. Academic Press; San Diego: 1990. p. 153-7. 
S. Preziuso et al. 